\title{
Oxidant-Redox Regulation of Pulmonary Vascular Responses to Hypoxia and Nitric Oxide-cGMP Signaling
}

\author{
Michael S. Wolin, Ph.D., Sachin A. Gupte, M.D., Ph.D. ${ }^{1}$, Boon Hwa Neo, B.A., Qun Gao, M.D., \\ Ph.D., and Mansoor Ahmad, M.D., Ph.D. \\ Department of Physiology and Pulmonary Hypertension Center New York Medical College, Valhalla, \\ NY 10595 \\ ${ }^{1}$ Department of Biochemistry \& Molecular Biology University of South Alabama, College of Medicine, \\ Mobile, AL 36688
}

\section{Abstract}

Most current theories for the mechanism of hypoxic pulmonary vasoconstriction (HPV) include a role for ROS and/or changes in redox regulation, but, extreme controversy exists regarding which systems and redox changes mediate the HPV response. Whereas, nitric oxide appears to help maintain low pulmonary arterial pressure, suppress HPV and to prevent the development of pulmonary hypertension. Our studies have found a key role for glucose-6-phosphate dehydrogenase in bovine pulmonary arterial smooth muscle functioning to maintain elevated levels of cytosolic NADPH which fuels the generation of vasodilator levels of hydrogen peroxide. HPV results from hypoxia removing vasodilation by peroxide. Decreased superoxide generation by Nox4 oxidase and its conversion to peroxide by $\mathrm{Cu}, \mathrm{Zn}$-SOD appear to be potential factors in sensing hypoxia, and decreased cGMP-associated vasodilation and removal of redox controlled vasodilator mechanisms by increased cytosolic NADPH may be key coordinators of the HPV response. Oxidant generation associated with vascular disease processes including the removal of $\mathrm{NO}$ by superoxide, and attenuation of its ability to stimulate cGMP production by oxidation of the heme and thiols of soluble guanylate cyclase attenuate potential beneficial actions of NO on pulmonary arterial function. While pulmonary hypertension appears to have multiple poorly understood effects on redox-associated processes potentially influencing responses to hypoxia and NO-cGMP signaling, much remains to be elucidated regarding how these processes maybe important factors in the progression, expression and therapeutic treatment of pulmonary hypertension.

\section{Keywords}

hypoxia; nitric oxide; pulmonary hypertension; redox signaling

\section{Roles for Oxidant-Redox Mechanisms in the Contractile Response of Pulmonary Arteries to Hypoxia}

The pulmonary circulation responds to hypoxia with vasoconstriction to optimize the matching of ventilation to perfusion in the lung. After extensive investigation of possible mechanisms for the hypoxic pulmonary vasoconstriction (HPV) response, recent work has focused on oxygen sensing mechanisms in pulmonary arterial smooth muscle cells because they appear to undergo contraction when resistance arteries of the lung are exposed to hypoxia in the

Corresponding Author: Michael S. Wolin, Ph.D., Professor, Department of Physiology, New York Medical College, Valhalla, NY 10595 Phone: 914-594-4093; Fax: 914-594-4826; mike_wolin@ nymc.edu. 
absence of other cell types ${ }^{1,2}$. In contrast, nitric oxide (NO) release from the pulmonary endothelium often appears to suppress the HPV response in a manner which may be altered by the physiological status of the pulmonary circulation and the progression of vascular disease processes ${ }^{3,4}$. Prolonged exposure of the pulmonary circulation to hypoxia in conditions such as high altitude sickness, COPD, etc elicits remodeling, especially in the smooth muscle layer, potentially originating from changes in the balance between $\mathrm{NO}$ and mechanisms involved in sensing hypoxia. In contrast to its effects on the pulmonary circulation, hypoxia usually elicits vasodilation in systemic circulations associated with improving the delivery of oxygen to tissues. Studies have also identified roles for endogenous nitric oxide in contributing factor to systemic hypoxic responses, and hypoxia also appears to relax systemic arterial smooth muscle ${ }^{5,6}$. The current theories of how oxygen is sensed by pulmonary arterial smooth muscle generally center around it modulating the biosynthesis of reactive oxygen species (ROS) such as hydrogen peroxide and/or changes in the oxidation-reduction or redox status of cellular metabolic systems such as cytosolic NADPH/NADP which are closely associated with the generation and metabolism of $\operatorname{ROS}^{7-9}$. Multiple components of cellular signaling mechanisms regulating vasodilation or vasoconstriction of vascular smooth muscle have sites which seem to be controlled by a redox process such as a change in the oxidation-reduction status of specific protein thiols. While nearly all current theories for the mechanism of HPV include a role for ROS and/or changes in redox regulation ${ }^{7-9}$, extreme controversy exists regarding which systems and redox changes mediate the HPV response. Our studies have found some redox regulatory properties of the HPV that may help resolve aspects of this controversy and document regulatory mechanisms which potentially contribute to disease-associated alterations in pulmonary vascular function.

\section{A. Theories on How Hypoxia Regulates Pulmonary Artery Function}

Most current theories on how the pulmonary artery senses oxygen tension focus on hypoxia altering the rate of production of a ROS by an oxidase enzyme present in vascular smooth muscle. Major controversy exists in areas such as whether hypoxia is increasing ${ }^{8}$ or decreasing ${ }^{7}, 9$ the generation of ROS, and which specific oxidase is the source of ROS being regulated. Sites of ROS generation in the proximal part of the mitochondrial electron transport chain in the region of Complex I and $\mathrm{III}^{7}, 8$ and/or NAD(P)H oxidase activity in cytosolic cellular regions ${ }^{9}$ are currently the major candidates being considered for their role in the oxygen sensing system regulating force in pulmonary arterial smooth muscle. Investigators in this field have also emphasized key roles for different redox regulated signaling mechanisms in mediating the contraction elicited by hypoxia. The redox theory for hypoxic vasoconstriction initially developed by Archer and Weir has proposed major roles for hypoxia decreasing the release of mitochondrial derived ROS (hydrogen peroxide) resulting in contraction through thiol oxidation causing membrane depolarization as a result of closure of cell surface potassium channels ${ }^{7}, 10,11$. Contrary to this hypothesis, Schumaker and colleagues have provided evidence for hypoxia increasing mitochondrial ROS in pulmonary arterial smooth muscle cells, and the resulting increase in peroxide promoting contraction through redox processes raising intracellular calcium levels ${ }^{8}$. Our studies have focused on comparing the origins of hypoxiaelicited contraction of bovine pulmonary arteries with the relaxation observed in bovine coronary arteries ${ }^{12}$. These studies have led to observations which may explain the origins of the differences between responses of these two vascular segments and why there is evidence for hypoxia both increasing and decreasing the detection of ROS in arterial smooth muscle.

\section{B. Potential Influence of Cytosolic NADPH redox and Hydrogen Peroxide}

Our initial work supported the redox theory of HPV by providing evidence for hypoxia promoting contraction through decreasing peroxide in the smooth muscle of pulmonary arteries 9,13 . We focused on $\mathrm{NAD}(\mathrm{P}) \mathrm{H}$ or Nox oxidase as the system sensing the decreased availability of oxygen in the hypoxic response based on initial observations on the influence 
of modulating this response with lactate and pyruvate through the lactate dehydrogenase reaction ${ }^{14}$. We found that lactate appeared to increase the availability of cytosolic NADH as a substrate or electron donor to oxygen for superoxide and peroxide formation by Nox oxidase in a manner which regulated the expression of the contraction to hypoxia in bovine pulmonary arteries. These studies evolved into data suggesting that peroxide derived from the generation of superoxide by Nox oxidase appeared to be causing a tonic relaxation of pulmonary arteries that was removed under hypoxia ${ }^{9}, 15$. As we tried to understand why pulmonary arteries showed increased levels of superoxide and a peroxide-mediated basal depression of force under aerobic conditions compared to coronary arteries, we observed that while both arteries had similar levels of Nox oxidase activity and expression of Nox 2 and Nox4, pulmonary arteries had increased NADPH and glucose-6-phosphate dehydrogenase (G6PD) activity ${ }^{16}$. Since we found evidence that inhibiting G6PD caused both a decrease in superoxide and vasodilation through NADPH oxidation coordinating multiple mechanisms of lowering intracellular calcium ${ }^{17}$, we hypothesized that the increased levels of NADPH in pulmonary arteries was driving the generation of increased superoxide-derived hydrogen peroxide in pulmonary arteries compared to coronary arteries. In addition, since exposure of coronary arteries to hypoxia elicited an oxidation of NADPH, we hypothesized that hypoxia was causing a metabolic stress that promoted relaxation of coronary arteries through cytosolic NADPH oxidation $^{6}$, and that the increased levels of G6PD in pulmonary arteries appeared to be functioning to prevent NADPH oxidation and relaxation to hypoxia seen in coronary arteries $^{16}$. As we studied relationships between NADH and NADPH redox changes with mitochondrial and cytosolic (extra-mitochondrial) superoxide in coronary arterial smooth muscle we found that hypoxia increased mitochondrial superoxide while it was decreasing cytosolic superoxide ${ }^{18}$. However, coronary arteries need to be partially contracted to observe relaxation to hypoxia, and contraction converted the increase in mitochondrial superoxide to a decrease. The controlling factor in regulating mitochondrial superoxide generation by hypoxia appeared to be mitochondrial NADH redox. Based on the cellular fluorescence of $\mathrm{NADH}$, mitochondrial NADH increased with hypoxia, but, this increase was converted to a decrease in contracted coronary arterial smooth muscle ${ }^{18}$. These observations are consistent with our evidence that changes in superoxide or peroxide do not appear to participate in the observed relaxation of coronary arteries to hypoxia ${ }^{6,19,20}$. In contrast, scavenging peroxide with ebselen or preventing peroxide production from superoxide by inactivating $\mathrm{Cu}$-dependent SOD activity (with diethyldithiocarbamate) increased force generation in pulmonary arteries and attenuated subsequent contraction to hypoxia suggesting that decreases in peroxide was a key factor in the observed HPV response ${ }^{21}$. Since our studies suggest that contracted pulmonary arteries show a decrease in superoxide and NADH-related tissue fluorescence potentially from mitochondria when they contract to hypoxia ${ }^{15}$ (P.M. Kaminski and M.S. Wolin, unpublished observations), they support evidence we have accumulated in bovine calf pulmonary arteries over the past 20 years suggesting hypoxia promotes contraction by removing a relaxation mediated by hydrogen peroxide (See Figure 1). While our studies indicate that inhibitors of mitochondrial electron transport (i. e. rotenone and antimycin) and inhibitors of Nox 2 oxidase activation by p47phox-related pathways (apocynin and gp91dstat) do not alter the contraction of pulmonary arteries to hypoxia, we investigated the role of Nox4 in the pulmonary artery response to hypoxia ${ }^{22,23}$. Since depletion of Nox4 by organ culturing pulmonary arteries with siRNA for this oxidase subunit was observed to attenuate contraction to hypoxia, attenuation of peroxide production derived from this oxidase may function as an oxygen sensor for hypoxia. Increasing Nox 4 expression by organ culture of pulmonary arteries with TGFß was also observed to enhance the HPV response ${ }^{24}$. A processes potentially contributing to the HPV response as a result of decreased consumption by Nox oxidase and the metabolism of peroxide is that hypoxia appears to increase NADPH in pulmonary $\operatorname{arteries}^{25,26}$. Thus, we have proposed based on our studies in isolated bovine pulmonary arteries that the mechanism of HPV originates from the ability of pulmonary arteries to maintain increased smooth muscle levels of cytosolic NADPH for maintaining a Nox4 oxidase-derived 
peroxide-mediated relaxation which is removed by hypoxia ${ }^{12}$. In this mechanism, an increase seen in $\mathrm{NADPH}^{26}$ potentially originating from a hypoxia decreasing NADPH consumption for both generating and metabolizing peroxide could also be a factor in promoting the contraction that is observed ${ }^{25}$.

\section{Is cGMP Signaling a Key Factor in the Response of Pulmonary Arteries to Hypoxia?}

Our early studies led us to focus on cGMP as a key signaling pathway mediating in the response of pulmonary arteries to hypoxia because we detected that peroxide was activating the soluble form of guanylate cyclase and increasing $\mathrm{cGMP}^{27}$, and hypoxia promoted contraction under conditions where it appeared to decrease both peroxide and cGMP ${ }^{13}$. It has become well established that increased cGMP protein kinase (PKG) activity in vascular smooth muscle functions to coordinate multiple processes shown in Figure 1 associated with lowering intracellular calcium that mediate relaxation ${ }^{28}$. Recently, a direct (cGMP-independent) activation of PKG by a peroxide-elicited thiol oxidation-mediated dimerization of PKG subunits was reported to function as a coronary artery vasodilator mechanism ${ }^{29}$, and we have confirmed that this mechanism is also activated in pulmonary arteries when they show relaxation to peroxide ${ }^{30}$. While the mechanisms controlling changes in force in HPV are quite controversial, our observations and the coordinating role of cGMP-PKG signaling in regulating multiple processes mediating relaxation makes it attractive for consideration as a key factor in controlling HPV.

\section{Roles for Oxidant-Redox Mechanisms in the Control of Nitric Oxide-cGMP Signaling}

Nitric oxide appears to have a modest role as a vasodilator in the pulmonary circulation under most basal physiological conditions where it has been studied, and endogenous NO seems to suppress the full expression of $\mathrm{HPV}^{3,}{ }^{4}$. Since NO inhibits proliferation of vascular smooth muscle cells, it may also function to prevent the remodeling associated with the development of pulmonary hypertension. Oxidant stress associated with pulmonary vascular pathophysiology may influence $\mathrm{NO}$ and the regulation of its $\mathrm{sGC}$ receptor in vascular smooth muscle by multiple mechanisms potentially important in the development and progression of pulmonary hypertension. In addition, oxidant stress-associated changes in NO-sGC regulation could also be a factor which has limited the beneficial effects of ventilating patents with NO gas as a therapy for treatment of pulmonary hypertension.

\section{A. The Role of Soluble Guanylate Cyclase and cGMP in the Actions of Nitric Oxide}

Stimulation of cGMP production by activation of the soluble form of guanylate cyclase (sGC) appears to be the most sensitive and dominant actions of NO in controlling pulmonary vascular function ${ }^{4}$. NO activates sGC by binding to a ferrous $\left(\mathrm{Fe}^{2+}\right)$ heme group which seems to be present on this enzyme under normal physiological conditions. Since NO is a dissolved gas, it readily diffuses through the vessel wall to sGC. In addition, NO is readily inactivated by any subcellular sites in the vessel wall where superoxide elevated by physiological stress or pathophysiology. The activation of PKG and signaling processes shown in Figure 1 regulated by PKG are thought to be primary factors in relaxation elicited by increases in cGMP ${ }^{28}$.

\section{B. Influence of Thiol and Heme Redox Processes in Controlling the Regulation of SGC and cGMP Signaling}

In addition to this well studied mechanism of inactivation of NO, other factors associated with sGC heme and thiol groups potentially have a major influence on the ability of NO to stimulate sGC (See Figure 2). We found that allowing cytosolic NADPH to oxidize by inhibiting G6PD exposes an inhibition of sGC activation by NO which appears to be controlled by increases in 
oxidized glutathione promoting a thiol oxidation on $\mathrm{sGC}^{31}$. In addition, agents which oxidize the heme of sGC such as the ODQ inhibitor and oxidants such as peroxynitrite cause an attenuation of $\mathrm{NO}$ relaxation because oxidation of the sGC heme prevents $\mathrm{NO}$ from stimulating cGMP production ${ }^{32}$. Our studies also suggest that a NADPH-dependent methemoprotein reductase also functions to maintain the heme of $\mathrm{sGC}$ in the ferrous of $\mathrm{Fe}^{2+}$ form needed for $\mathrm{NO}$ binding and activation of $\mathrm{sGC}^{33}$. Thus, when heme or glutathione redox regulated thiol sites on SGC are oxidized by conditions likely to be associated with the oxidant stress of vascular disease processes, the sensitivity of sGC to activation by NO will be markedly attenuated.

\section{Relationships Between Heme Metabolism and the Regulation of sGC}

There are several relationships between heme metabolism and sGC that are likely to be essential for the maintenance of the beneficial effects of cGMP-dependent regulation of pulmonary vascular function. When oxidant stress of vascular disease processes oxidizes the heme of sGC, it also causes a loss of heme and a degradation of $\mathrm{sGC}^{32}$. Thus, heme biosynthesis from deltaaminolevulinic acid in the mitochondria and the maintenance of heme reduction are essential for normal stimulation of sGC. Many vascular disease processes increase the expression of heme oxygenase-1 (HO-1) $)^{34}$, an enzyme associated with several routes of influencing sGC. Increased HO-1 expression can deplete cellular heme to the extent that it causes a loss of sGC stimulation by $\mathrm{NO}^{35}$. However, a more dominant effect of increased heme oxygenase activity seems to result from it promoting increased expression of the extracellular form of SOD (ecSOD). Increased ecSOD appears to both restore endothelium-dependent relaxation to NO in vascular disease models such as diabetes ${ }^{36}$, and the increase in peroxide formed can potentially have other actions such at attenuating the contractile effects of pulmonary arteries to hypoxia ${ }^{21}$. Both of these actions of increased HO-1 expression could potentially function to attenuate the development of pulmonary hypertension. While the vasodilator effects of carbon monoxide (CO) generated by the HO-reaction were initially emphasized, this action of $\mathrm{CO}$ seems to occur at relatively high concentrations which may limit its relevance as a pulmonary vasodilator. We have found that exposure of pulmonary arteries to deltaaminolevulinic acid in organ culture results in the accumulation of the heme-precursor protoporphyrin $\mathrm{IX}^{37}$, an agent which binds the heme site of sGC in a manner which markedly promotes increased cGMP generation ${ }^{38}$. While this mechanism seems to function as a vasodilator in pulmonary arteries ${ }^{37}$, it is not known if this mechanism has a role in pulmonary vascular regulation. However, drugs have been developed to bind sGC in a manner similar to protoporphyrin IX which show promise for the treatment of pulmonary hypertension ${ }^{39}$.

\section{Influence of Pulmonary Hypertension on Hypoxic and NO-cGMP Signaling}

Pulmonary hypertension appears to have multiple effects on processes potentially influencing responses to hypoxia and NO-cGMP signaling, but, the overall consequences of these changes seem rather poorly understood. There is evidence for impaired endothelial generation of NO which could potentially originate from altered NO synthase regulation and/or increased oxidant production ${ }^{4}$. While sGC expression has been reported to be increased in pulmonary hypertension ${ }^{40}$, there is a lack of evidence for enhanced sensitivity to NO suggesting disease processes attenuate the ability of NO to activate sGC. While pulmonary hypertension is generally associated with increased oxidant stress, the role of oxidant stress in the progression of pulmonary hypertension and altered vascular reactivity is not well defined ${ }^{41}, 42$. Hypoxia promotes the development of pulmonary hypertension in animals, but, it is not well established if mechanisms associated with the HPV response seen at elevated pulmonary artery pressure have been markedly changed. Sildenafil-like phosphodiesterase inhibitors which function through increasing cGMP have been shown to be beneficial in the treatment of pulmonary hypertension ${ }^{43}$. Newer drugs under development which activate sGC in a heme-dependent and 
NO-enhancing manner, as well as agents which stimulate sGC through the protoporphyrin IX site show potential therapeutic benefit for the treatment of pulmonary hypertension ${ }^{39,44}$. While increasing cGMP also appears to be beneficial in reversing the right heart failure that is associated with pulmonary hypertension ${ }^{43}$, a recent study in animals suggests the therapeutic effects on lowering pulmonary artery pressure may be more important than the direct effects of cGMP-increasing drugs on cardiac muscle ${ }^{45}$. Thus, poorly understood redox processes contributing to pulmonary vascular regulation by hypoxia, NO and cGMP signaling are likely to important factors in the progression, expression and therapeutic treatment of pulmonary hypertension.

\section{Acknowledgments}

The work of the authors has been supported by an American Heart Association Scientist Development Grant 0435070N (SAG) and by NIH Grants HL085352 (SAG), HL031069, HL043023, and HL066331 (MSW).

\section{References}

1. Omar HA, Wolin MS. Endothelium-dependent and independent cGMP mechanisms appear to mediate $\mathrm{O}_{2}$ responses in calf pulmonary resistance arteries. Am J Physiol 1992;262:L560-565. [PubMed: 1317116]

2. Michelakis ED, Hampl V, Nsair A, et al. Diversity in mitochondrial function explains differences in vascular oxygen sensing. Circ Res 2002;90:1307-1315. [PubMed: 12089069]

3. Le Cras TD, McMurtry IF. Nitric oxide production in the hypoxic lung. Am J Physiol Lung Cell Mol Physiol 2001;280:L575-582. [PubMed: 11237994]

4. Coggins MP, Bloch KD. Nitric oxide in the pulmonary vasculature. Arterioscler Thromb Vasc Biol 2007;27:1877-1885. [PubMed: 17541026]

5. Duncker DJ, Bache RJ. Regulation of coronary blood flow during exercise. Physiol Rev 2008;88:10091086. [PubMed: 18626066]

6. Gupte SA, Wolin MS. Hypoxia promotes relaxation of bovine coronary arteries through lowering cytosolic NADPH. Am J Physiol Heart Circ Physiol 2006;290:H2228-2238. [PubMed: 16415080]

7. Moudgil R, Michelakis ED, Archer SL. Hypoxic pulmonary vasoconstriction. J Appl Physiol 2005;98:390-403. [PubMed: 15591309]

8. Waypa GB, Schumacker PT. Hypoxic pulmonary vasoconstriction: redox events in oxygen sensing. J Appl Physiol 2005;98:404-414. [PubMed: 15591310]

9. Wolin MS, Ahmad M, Gupte SA. Oxidant and redox signaling in vascular oxygen sensing mechanisms: basic concepts, current controversies, and potential importance of cytosolic NADPH. Am J Physiol Lung Cell Mol Physiol 2005;289:L159-173. [PubMed: 16002998]

10. Archer SL, Will JA, Weir EK. Redox status in the control of pulmonary vascular tone. Herz 1986;11:127-141. [PubMed: 3017827]

11. Archer SL, Huang J, Henry T, Peterson D, Weir EK. A redox-based $\mathrm{O}_{2}$ sensor in rat pulmonary vasculature. Circ Res 1993;73:1100-1112. [PubMed: 8222081]

12. Wolin MS. Reactive oxygen species and the control of vascular function. Am J Physiol Heart Circ Physiol 2009;296:H539-549. [PubMed: 19151250]

13. Burke-Wolin TM, Wolin MS. $\mathrm{H}_{2} \mathrm{O}_{2}$ and cGMP may function as an $\mathrm{O}_{2}$ sensor in the pulmonary artery. J Appl Physiol 1989;66:167-170. [PubMed: 2537281]

14. Omar HA, Mohazzab-H KM, Mortelliti MP, Wolin MS. $\mathrm{O}_{2}$-dependent modulation of calf pulmonary artery tone by lactate: potential role of $\mathrm{H}_{2} \mathrm{O}_{2}$ and cGMP. Am J Physiol 1993;264:L141-145. [PubMed: 8383445]

15. Mohazzab-H KM, Fayngersh RP, Kaminski PM, Wolin MS. Potential role of NADH oxidoreductasederived reactive $\mathrm{O}_{2}$ species in calf pulmonary arterial $\mathrm{PO}_{2}$-elicited responses. Am J Physiol 1995;269:L637-644. [PubMed: 7491983]

16. Gupte SA, Kaminski PM, Floyd B, et al. Cytosolic NADPH may regulate differences in basal Nox oxidase-derived superoxide generation in bovine coronary and pulmonary arteries. Am J Physiol Heart Circ Physiol 2005;288:H13-21. [PubMed: 15345489] 
17. Gupte SA, Arshad M, Viola S, et al. Pentose phosphate pathway coordinates multiple redox-controlled relaxing mechanisms in bovine coronary arteries. Am J Physiol Heart Circ Physiol 2003;285:H23162326. [PubMed: 12933338]

18. Gao Q, Wolin MS. Effects of hypoxia on relationships between cytosolic and mitochondrial NAD (P)H redox and superoxide generation in coronary arterial smooth muscle. Am J Physiol Heart Circ Physiol 2008;295:H978-H989. [PubMed: 18567707]

19. Mohazzab-H KM, Kaminski PM, Fayngersh RP, Wolin MS. Oxygen-elicited responses in calf coronary arteries: role of $\mathrm{H}_{2} \mathrm{O}_{2}$ production via NADH-derived superoxide. Am J Physiol 1996;270:H1044-1053. [PubMed: 8780202]

20. Mohazzab-H KM, Agarwal R, Wolin MS. Influence of glutathione peroxidase on coronary artery responses to alterations in $\mathrm{PO}_{2}$ and $\mathrm{H}_{2} \mathrm{O}_{2}$. Am J Physiol 1999;276:H235-241. [PubMed: 9887037]

21. Ahmad M, Zhao X, Kelly MR, et al. Heme oxygenase-1 induction modulates hypoxic pulmonary vasoconstriction through upregulation of ecSOD. Am J Physiol Heart Circ Physiol 2009;297:H14531461. [PubMed: 19666846]

22. Ahmad M, Kaminski PM, Wolin MS. Modulation of the Contractile Response of Bovine Pulmonary Arteries to Hypoxia by Plumbagin, an inhibitor of Nox oxidase-4. FASEB J 2007;21:A922.

23. Ahmad M, Kelly MR, Kandhi S, Zhao X, Wolin MS. Nox-4 siRNA Causes Attenuation of Hypoxic Pulmonary Vasoconstriction in Bovine Pulmonary Arteries. FASEB J 2009;23:1002-1008.

24. Ahmad M, Zhao X, Kelly MR, Kaminski PM, Wolin MS. TGF $\beta-1$ mediated increase in Nox-4 expression enhances hypoxic pulmonary vasoconstriction in bovine pulmonary arteries. FASEB J 2008;22:1152-1122.

25. Wolin MS, Ahmad M, Gao Q, Gupte SA. Cytosolic NAD(P)H regulation of redox signaling and vascular oxygen sensing. Antioxid Redox Signal 2007;9:671-678. [PubMed: 17511583]

26. Gupte SA, Okada T, McMurtry IF, Oka M. Role of pentose phosphate pathway-derived NADPH in hypoxic pulmonary vasoconstriction. Pulm Pharmacol Ther 2006;19:303-309. [PubMed: 16203165]

27. Burke TM, Wolin MS. Hydrogen peroxide elicits pulmonary arterial relaxation and guanylate cyclase activation. Am J Physiol 1987;252:H721-732. [PubMed: 2882694]

28. Lincoln TM, Dey N, Sellak H. Invited review: cGMP-dependent protein kinase signaling mechanisms in smooth muscle: from the regulation of tone to gene expression. J Appl Physiol 2001;91:14211430. [PubMed: 11509544]

29. Burgoyne JR, Madhani M, Cuello F, et al. Cysteine redox sensor in PKGIa enables oxidant-induced activation. Science 2007;317:1393-1397. [PubMed: 17717153]

30. Neo BH, Kandhi S, Wolin MS. Potential Role of a Thiol Oxidation-Elicited Subunit Dimerization Activation of Protein Kinase $\mathrm{G}$ in the Relaxation of Pulmonary Arteries to Hydrogen Peroxide. FASEB J 2009;23:1002-1006.

31. Mingone CJ, Gupte SA, Ali N, Oeckler RA, Wolin MS. Thiol oxidation inhibits nitric oxide-mediated pulmonary artery relaxation and guanylate cyclase stimulation. Am J Physiol Lung Cell Mol Physiol 2006;290:L549-557. [PubMed: 16272175]

32. Stasch JP, Schmidt PM, Nedvetsky PI, et al. Targeting the heme-oxidized nitric oxide receptor for selective vasodilatation of diseased blood vessels. J Clin Invest 2006;116:2552-2561. [PubMed: 16955146]

33. Gupte SA, Rupawalla T, Phillibert D Jr. Wolin MS. NADPH and heme redox modulate pulmonary artery relaxation and guanylate cyclase activation by NO. Am J Physiol 1999;277:L1124-1132. [PubMed: 10600882]

34. Abraham NG, Kappas A. Pharmacological and clinical aspects of heme oxygenase. Pharmacol Rev 2008;60:79-127. [PubMed: 18323402]

35. Mingone CJ, Ahmad M, Gupte SA, Chow JL, Wolin MS. Heme oxygenase-1 induction depletes heme and attenuates pulmonary artery relaxation and guanylate cyclase activation by nitric oxide. Am J Physiol Heart Circ Physiol 2008;294:H1244-1250. [PubMed: 18178725]

36. Turkseven S, Kruger A, Mingone CJ, et al. Antioxidant mechanism of heme oxygenase-1 involves an increase in superoxide dismutase and catalase in experimental diabetes. Am J Physiol Heart Circ Physiol 2005;289:H701-707. [PubMed: 15821039] 
37. Mingone CJ, Gupte SA, Chow JL, Ahmad M, Abraham NG, Wolin MS. Protoporphyrin IX generation from delta-aminolevulinic acid elicits pulmonary artery relaxation and soluble guanylate cyclase activation. Am J Physiol Lung Cell Mol Physiol 2006;291:L337-344. [PubMed: 16899710]

38. Wolin MS, Wood KS, Ignarro LJ. Guanylate cyclase from bovine lung. A kinetic analysis of the regulation of the purified soluble enzyme by protoporphyrin IX, heme, and nitrosyl-heme. J Biol Chem 1982;257:13312-13320. [PubMed: 6128335]

39. Dumitrascu R, Weissmann N, Ghofrani HA, et al. Activation of soluble guanylate cyclase reverses experimental pulmonary hypertension and vascular remodeling. Circulation 2006;113:286-295. [PubMed: 16391154]

40. Schermuly RT, Stasch JP, Pullamsetti SS, et al. Expression and function of soluble guanylate cyclase in pulmonary arterial hypertension. Eur Respir J 2008;32:881-891. [PubMed: 18550612]

41. Huang J, Kaminski PM, Edwards JG, et al. Pyrrolidine dithiocarbamate restores endothelial cell membrane integrity and attenuates monocrotaline-induced pulmonary artery hypertension. Am J Physiol Lung Cell Mol Physiol 2008;294:L1250-1259. [PubMed: 18390833]

42. Gupte SA, Wolin MS. Oxidant and redox signaling in vascular oxygen sensing: implications for systemic and pulmonary hypertension. Antioxid Redox Signal 2008;10:1137-1152. [PubMed: 18315496]

43. Wilkins MR, Wharton J, Grimminger F, Ghofrani HA. Phosphodiesterase inhibitors for the treatment of pulmonary hypertension. Eur Respir J 2008;32:198-209. [PubMed: 18591337]

44. Ghofrani HA, Grimminger F. Soluble guanylate cyclase stimulation: an emerging option in pulmonary hypertension therapy. Eur Respir Rev 2009;18:35-41.

45. Schafer S, Ellinghaus P, Janssen W, et al. Chronic inhibition of phosphodiesterase 5 does not prevent pressure-overload-induced right-ventricular remodelling. Cardiovasc Res 2009;82:30-39. [PubMed: 19131365] 


\section{Hypoxia}

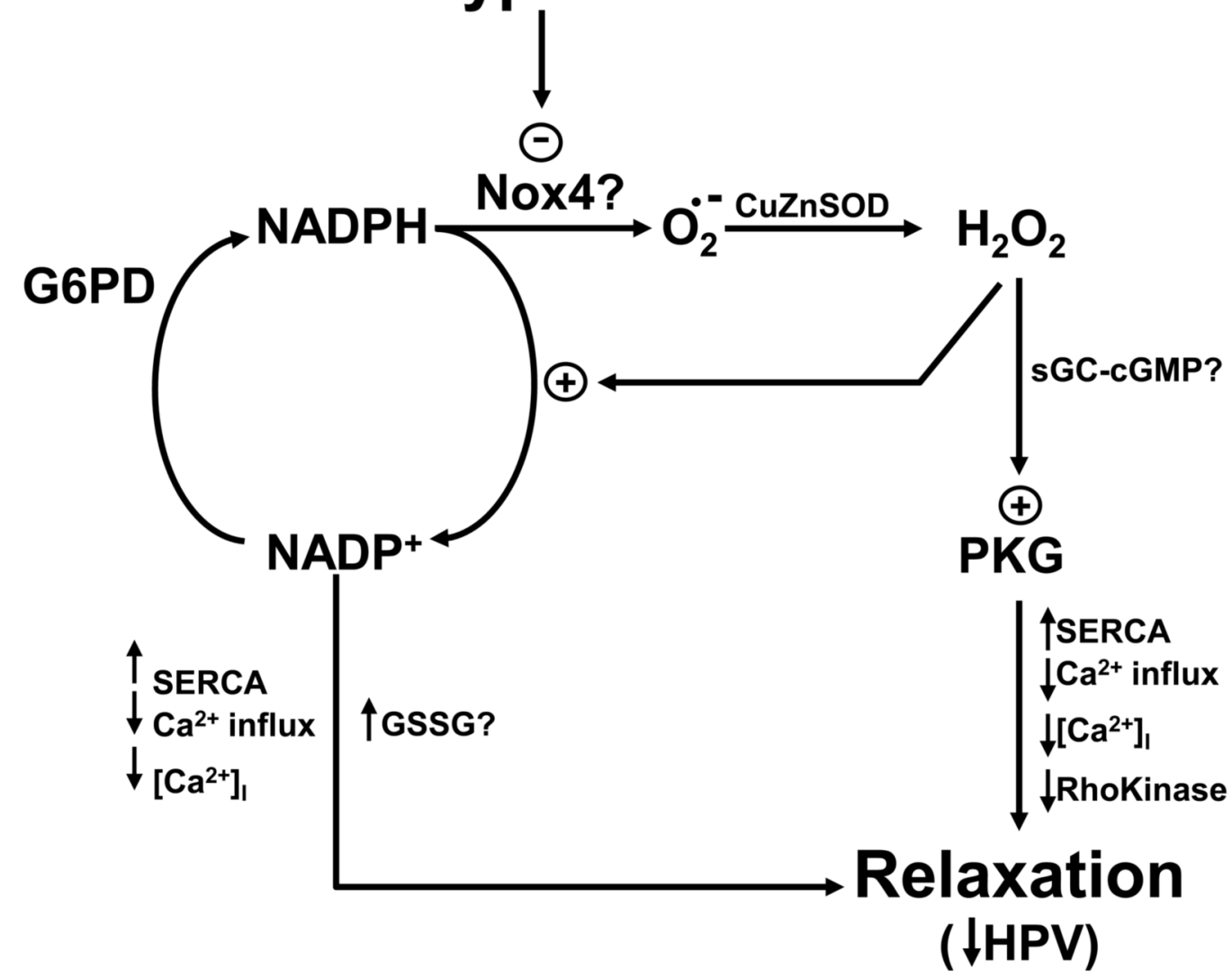

Fig. 1.

Model showing how hypoxia is hypothesized to elicit a hypoxic pulmonary vasoconstriction (HPV) response seen in bovine pulmonary arteries by removal of a relaxation by hydrogen peroxide which appears to be derived from Nox4 oxidase. The model shows how hypoxia decreases the generation of superoxide $\left(\mathrm{O}_{2}{ }^{-}\right)$by Nox4 oxidase needed for conversion to hydrogen peroxide by $\mathrm{Cu}, \mathrm{Zn}-\mathrm{SOD}$ and mechanisms through which peroxide can maintain a relaxation under normoxic conditions potentially mediated through stimulation of cGMPdependent protein kinase (PKG) activity. In addition, by hypoxia decreasing cytosolic NADPH consumption for the generation and metabolism of peroxide, it may also reverse relaxing mechanisms controlled by cytosolic NADPH oxidation and oxidized glutathione (GSSG) formation. In this model, the relaxing mechanisms removed by hypoxia may involve decreasing intracellular calcium $\left[\mathrm{Ca}^{2+}\right]_{\mathrm{I}}$ (e.g. through increased uptake by the SERCA pump and decreased $\mathrm{Ca}^{2+}$ influx) and suppressing the action of $\mathrm{Ca}^{2+}$ on the contractile apparatus through inhibiting Rho kinase activity. 


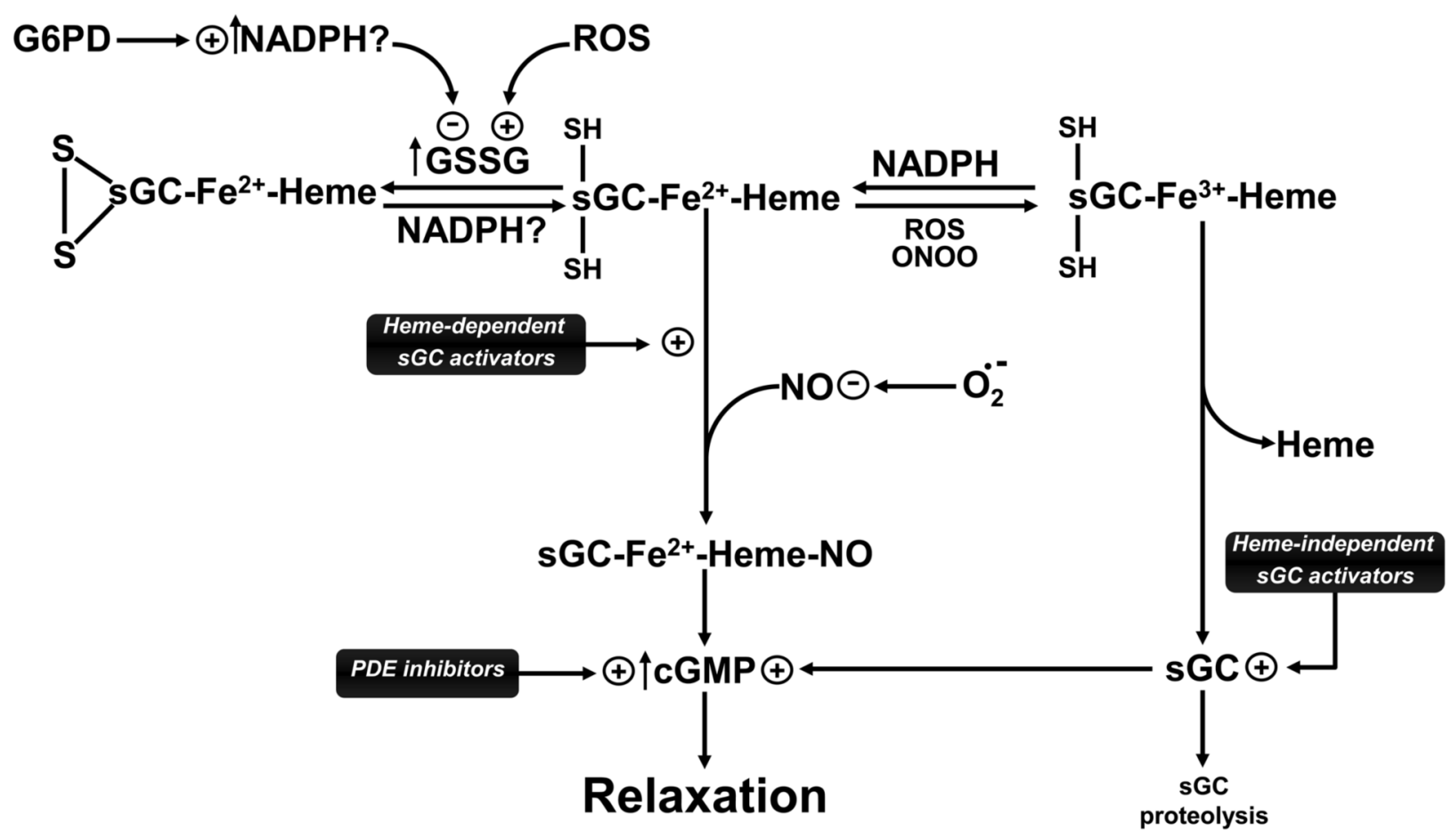

Fig. 2.

Model showing how multiple oxidant mechanisms potentially associated with the progression of vascular disease processes can attenuate endogenous nitric oxide (NO) vasodilation mediated through stimulation of cGMP production by soluble guanylate cyclase (sGC), and how new therapies being developed for the to treat pulmonary hypertension potentially function through restoring cGMP-mediated relaxation. Oxidant processes associated with the formation of reactive oxygen species (ROS), peroxynitrite (ONOO) and oxidized glutathione (GSSG), etc. can inhibit NO-mediated increases in cGMP by superoxide $\left(\mathrm{O}_{2}{ }^{-}\right)$directly oxidizing NO to ONOO, and by attenuating the ability of sGC to be activated by NO through oxidation of iron $(\mathrm{Fe})$ of heme and thiol sites $(\mathrm{SH})$ on sGC. The model also shows the potential importance of how the regulation of cytosolic NADPH generation by glucose-6-phopshate dehydrogenase (G6PD) reaction potentially functions at multiple sites to reverse the effects of heme and thiol oxidation, and how therapeutically beneficial drugs inhibiting removal of cGMP by phosphodiesterases (PDE, e.g. Sildenafil) function to reverse pulmonary hypertension. 